\title{
Study of Impact of 3D Printing Technology and Development on Creative Industry
}

\author{
Zhang Feixiang (Corresponding author) \\ College of Communication and Art Design, University of Shanghai for Science and \\ Technology, Shanghai, China \\ E-mail: zhangfx2000@sina.com
}

Zong Liyong

Shanghai Publishing and Printing College, Shanghai, China

Kuang Xia

Shanghai Publishing and Printing College, Shanghai, China

Received: January 28, 2016 Accepted: February 23, 2016 Published: February 25, 2016

doi: 10.5296/jsss.v3i2.9106 URL: http://dx.doi.org/10.5296/jsss.v3i2.9106

\begin{abstract}
This paper simply makes an introduction to 3D printing technology. Application Value of 3D Printing Technology in Creative Industry and Its Industrial Significance are discussed. Besides, the paper analyses the changes of creative industry because of 3D printing technology development, and finally some relevant policies are suggested.

Keywords: Creative industry, 3D printing, Frontier technology, Knowledge map

\section{Introduction}

Cultural creative industry whose core value is cultural content and creative achievements is characterized by the realization of intellectual property rights or the consumption for trading with innovation and creation as a fundamental means. Cultural creative industries in the process of development, especially in the creative design phase has more obvious and more direct dependence on science and technology. With the diversified development of 3D printing materials and printing technology innovation, 3D printing not only displays the huge development potential in the traditional manufacturing industry but also extends to the
\end{abstract}


cultural creative industry, such as the film and television media, environmental art, advertising and decoration, costume design and creative design and so on. 3D printing technology is a key technology pushing the technology development of model design, advertising design, architectural design technology in the future as the new technology in which industry production and art creation mix and integrate. 3D printing technology will facilitate the leap development of art design and industrial design in a new generation with its constant improvement.

\subsection{Introduction of $3 D$ Printing}

$3 \mathrm{D}$ printing has developed significantly over the past 30 years. A new industrial revolution is coming due to smaller and more portable commercial 3D printers and the technology has become accessible to businesses across many industries.

$3 \mathrm{D}$ printing adopts an additive manufacturing process whereby products are built on a layer-by-layer basis, through a series of cross-sectional slices. All 3D printers use 3D-CAD software that ensures thousands of cross-sections of each product to determine exactly how each layer is to be constructed. In phase one of 3D printing, architects, artists, and product designers used 3D printing technology to make prototypes or mockups of new designs. 3D printers have several key advantages including (1) ease of duplicating products, (2) low cost, and (3) product security and privacy considerations and so on (Barry, 2012). 3D printing is an example of a disruptive technology, which plays a role in a new market that older technology cannot. As companies go about their business of catering to their most profitable customers and proven market segments, 3D printing may find an entry-point in the low-end markets of many different products. 3D printing is inferior to traditional manufacturing methods such as molding or machining, and is also more expensive. However, it is more convenient and customizable (Anderson et al., 2007).

\section{Application Value of 3D Printing Technology in Creative Industry and Its Industrial Significance}

With 3D fast development in technology and its wide application in different fields, it is highly expected in the development of creative industry. The continuous development of information technology, the design of software and digital tools has laid a solid foundation for the further application of 3D printing. The application value and industrial significance of 3D printing technology in the cultural creative industry can be reflected in the following aspects:

(1) The emergence of 3D printing shortens the cycle of design and development for solid cultural and creative products. The rise of $3 \mathrm{D}$ printing makes it possible to manufacture personalized products at small scale in a short period of time. The application of $3 \mathrm{D}$ printing increases the efficiency and promotes product development and industrial designing in the design industry as well as avoiding the risk of intellectual property leakage due to prototyping production outsourcing.

(2) 3D printing provides the possibility of building complex solid models for relevant cultural and creative industry. 3D printing is a convenient tool to develop complex form solid models and can offer designers an efficient and convenient solution because it not only creates conditions for the external complex morphology of products but also for the creativity of their 
internal structures.

(3) Personalized innovation is more advocated in value propositions of 3D printing business models. In terms of value creation, it brings great changes to the production mode such as the conversion of mass production to small batch customization, which makes originally sophisticated products in the industry achieve "personalized customization". Therefore, 3D printing changes the model of mass production and mass sale in the traditional manufacturing industry, forming a new economic growth point. With 3D printing, users can be involved in the creation and put forward and complete their needs instead of accepting passively.

\section{Changes of Creative Industry Caused by 3D Printing Technology Development}

(1) With the development of 3D printing, production pattern changes from the centralization and mass specialized manufacturing in the past into decentralized and small-batch socialized manufacturing. The rapid development of information technology and advanced design tools provide a good technology support for 3D printing technology. In spite of 3D printing development for more than a decade, 3D printing industry has the limited radiation effect on the cultural and creative industries with poor business models in its early development stage. With the increasingly mature 3D printing technology, independent designers depend on the traditional processing industry less and less. Instead, each consumer may become a designer and manufacturer and $3 \mathrm{D}$ printing will further change the present pattern of art and industrial design industry.

(2) In terms of the industrial chain of 3D printing, technological breakthrough will be made in two aspects of modeling and consumables in the future. The difficulty of the upstream of 3D printing industry chain is mainly technical. At present, the more advanced technology is the use of holographic technology to get image by scanning the object, and then to reconstruct 3D models through the computer vision and photogrammetry technology. Breakthroughs in modeling technology will reduce the operating cost of the whole industry, so as to develop a broader market. In terms of materials, although 3D printing technology has made a lot of progress in recent years, such as more printing materials, and reducing prices of printers and printing materials, 3D printing will not be adopted by enterprises on a large scale (Huang Guoguang,2013) as a young technology before it becomes much maturer and cheaper. For material industry, the competition between print material providers and the role of market rules will eventually facilitate the formation of $3 \mathrm{D}$ printing materials market standards, which is helpful for 3D printing to build a mature industrial chain.

(3) In terms of business models, crowdsourcing model for enterprises in cultural and creative industry will become an important way for 3D printing technology to achieve its business value. With socialized manufacturing brought about by 3D printing technology, the new socialized design pattern- "design crowdsourcing" will be popular too (Zhang et al., 2013). Crowdsourcing model has been much recommended and applied in many fields and become a new driving force for the innovation of service outsourcing. Online collaborative production of crowdsourcing form makes 3D model building and modification a routine work. The current popular mass customization, mass collaborative production all emphasize the absorption of consumers' will or innovative ideas into the production process to promote the innovation in the production and products meeting consumers' diversified demands. 
(4) The wide application of 3D printing technology separates the product design and manufacturing, so designers need to constantly strengthen and improve their understanding of the design theory, its application and development. First of all, designers will directly spread and teach to consumers the corresponding design theories; Second, as a trading goods, design contains comprehensive information such as designers' individual behavior, their design idea construction and market performance (Song et al., 2013). The stronger interaction between designers and users can make design satisfaction get real feedback, changing the course of value creation which gets more personalized, humanized and niche.

\section{Suggestions on Policies to Promote 3D Printing Technology in Creative Industry}

(1) The knowledge map analysis shows the key technology is lacking although the current 3D printing technology can meet the needs of the innovation and development of cultural and creative industry. Tools of model scanning and motion capture in $3 \mathrm{D}$ printing need a series of technical support, such as model collection device and application software and so on, involving the simulation technology, computer graphics technology, data transmission technology, etc., which fail to appear in the hot research field. Without the support of these technical platforms, the development of 3D printing technology will be subject to sources of printing prototype materials. Therefore, the development of the research and development platform of 3D scanning and modeling technology with independent intellectual property rights should be given priority in industry planning, helping improve product research and development in industrial and art design fields, and extend the application of 3D printing.

(2) The cultural and creative industry in our country has gained a foothold in the international competition with 3D printing. But the development of cultural and creative industry not only depends on the technically competitive advantages but more on providing appropriate business environment for the technology development in the long run. Therefore, industrial development and guidance policy need to focus on the top design of 3D printing technology and the cultural and creative industry development, need to develop 3D printing industry development plan to promote its development in the first place Wang (Zhong et al., 2013). Domestic commercialization process in $3 \mathrm{D}$ printing is relatively slow, and the relatively complete industrial chain has not been formed yet. There still exist some problems in changes arising from 3D printing, which calls for financial support from related government departments.

(3) Related plans in art and industrial design industry and the intelligence manufacturing need to pay attention to the impact of technology optimization on the industry. Differentiation of the industry can create new divisions of labor. For the software industry, with more kinds of 3D graphics software, 3D printing makes 3D model designers the mainstream designing crowd, forming modeling industry of 3D printing upstream industry. The development of 3D printing industry need to share industrial resources and services and a complete industry chain can promote the development of the whole industry cluster.

(4) It is time some of government department such as Industrial Informatization Department and Ministry of Commerce set up a sound system of laws and regulations and supervise the implementation of 3D printing related laws, regulations and policies of management. 3D printing technology has been widely applied in the fields of industrial design, medicine, and personalized design and will have a promising prospects with its development. But 3D itself 
contains a certain inherent risk - intellectual property, dangerous goods and human morality, and so on (Liu, 2013). All of these risks will become the key constraining factors and bottleneck of 3D printing development if these related supervision problems arising from technology evolution can not be reasonably addressed. Therefore, policy makers and related industry departments need to figure out proactive management measures to deal with the possible problems in the 3D printing development.

\section{Acknowledgements}

Fund projects:

1). 2012 National Social Science Fund Project-"Promoting the Strategic Dimensions of the Cultural Industry as a Pillar Industry of the National Economy and the Support System" (12 \& ZD024).

2). Scientific Research Innovation Supported by Shanghai Educational Committee- "Study of Impact of Shanghai Fiscal Cultural Input on Creative Industry" (14YS046).

3). The Key Research Project of Shanghai Financial Promotion Fund for the Development of Cultural Creative Industry-"Research on Development of Frontier Technology Application in Cultural Creative Industry Field” (2013020015).

\section{References}

Anderson, P., \& Sherman, C. A. (2007). A discussion of new business models for 3D printing. International Journal of Technology Marketing, 2(3), 280-294. http://dx.doi.org/10.1504/IJTMKT.2007.015205

Barry, B., \& Business, H. (2012). 3-D printing. The New Industrial Revolution, 55, 155-162.

Huang, G. (2013). 3D printing - Digital Manufacturing Technology. Screen Printing, 5, 32-38.

Liu, B. (2013). Inherent Risks of 3D Printing Technology and Its Policy and Legal Norms. Science and Economy and Society, 31(2), 130-132.

Song, J., \& Yang, L. (2013). Product Green Design Based on Application of 3D Printing Technology. Journal of LanZhou JiaoTong University, 32(5), 116-119.

Wang, Z., Li, Y., \& Zhang, M. (2013). 3D printing Industry in China and Thoughts on Its Development. Economic Review, 1, 90-93.

Zhang, N., \& Li, F. (2013). The Impact of Development and Application of 3D printing technology on Product Design in the Future. Journal of Machine Design, 30(7), 97-99.

\section{Copyright Disclaimer}

Copyright for this article is retained by the author(s), with first publication rights granted to the journal.

This is an open-access article distributed under the terms and conditions of the Creative Commons Attribution license (http://creativecommons.org/licenses/by/3.0/). 